\title{
Circadian Rhythms and Obesity in Mammals
}

\author{
Oren Froy \\ Institute of Biochemistry, Food Science and Nutrition, Robert H. Smith Faculty of Agriculture, Food and Environment, \\ The Hebrew University of Jerusalem, P.O. Box 12, 76100 Rehovot, Israel \\ Correspondence should be addressed to Oren Froy, oren.froy@mail.huji.ac.il \\ Received 16 October 2012; Accepted 11 November 2012 \\ Academic Editors: M. Delibegovic and Z. Wang \\ Copyright (C) 2012 Oren Froy. This is an open access article distributed under the Creative Commons Attribution License, which \\ permits unrestricted use, distribution, and reproduction in any medium, provided the original work is properly cited. \\ Obesity has become a serious public health problem and a major risk factor for the development of illnesses, such as insulin resis- \\ tance and hypertension. Attempts to understand the causes of obesity and develop new therapeutic strategies have mostly focused \\ on caloric intake and energy expenditure. Recent studies have shown that the circadian clock controls energy homeostasis by reg- \\ ulating the circadian expression and/or activity of enzymes, hormones, and transport systems involved in metabolism. Moreover, \\ disruption of circadian rhythms leads to obesity and metabolic disorders. Therefore, it is plausible that resetting of the circadian \\ clock can be used as a new approach to attenuate obesity. Feeding regimens, such as restricted feeding (RF), calorie restriction \\ (CR), and intermittent fasting (IF), provide a time cue and reset the circadian clock and lead to better health. In contrast, high-fat \\ (HF) diet leads to disrupted circadian expression of metabolic factors and obesity. This paper focuses on circadian rhythms and \\ their link to obesity.
}

\section{Introduction}

Obesity has become a serious and growing public health problem [1]. Attempts to develop new therapeutic strategies have mostly focused on energy expenditure and caloric intake. Recent studies link energy homeostasis to the circadian clock at the behavioral, physiological, and molecular levels [2-5], emphasizing that certain nutrients and the timing of food intake may play a significant role in weight gain [6]. Therefore, it is plausible that resetting of the circadian clock can be used as a new approach to attenuate obesity.

\section{Circadian Rhythms}

Our planet revolves around its axis causing light and dark cycles of 24 hours. Organisms on our planet evolved to predict these cycles by developing an endogenous circadian (circa: about and dies: day) clock, which is synchronized to external time cues. This way, organisms ensure that physiological processes are carried out at the right time of the circadian cycle [7]. All aspects of physiology, including sleepwake cycles, cardiovascular activity, endocrine system, body temperature, renal activity, gastrointestinal tract motility, and metabolism, are influenced by the circadian clock [7, 8]. Indeed, $10-20 \%$ of all cellular transcripts are cyclically expressed, most of which are tissue-specific [2, 9-13].

\section{The Circadian Clock}

The central circadian clock is located in the suprachiasmatic nuclei (SCN) of the brain anterior hypothalamus. The SCN clock is composed of multiple, single-cell oscillators synchronized to generate circadian rhythms $[8,14-16]$. The endogenous period of the SCN oscillation is approximately, but not exactly, $24 \mathrm{~h}$. Therefore, it requires resetting each day to the external light-dark cycle to prevent drifting out of phase. Light is a strong synchronizer for the brain clock, perceived by the retina and transmitted via the retinohypothalamic tract (RHT) to the SCN [17-19]. Similar clocks are found in peripheral tissues, such as the liver, intestine, and retina [20-22] (Figure 1). Complete destruction of the SCN abolishes circadian rhythmicity in the periphery leading to arrhythmicity $[23,24]$. The SCN transmits the information to peripheral oscillators to prevent the dampening of circadian rhythms via neuronal connections or circulating 


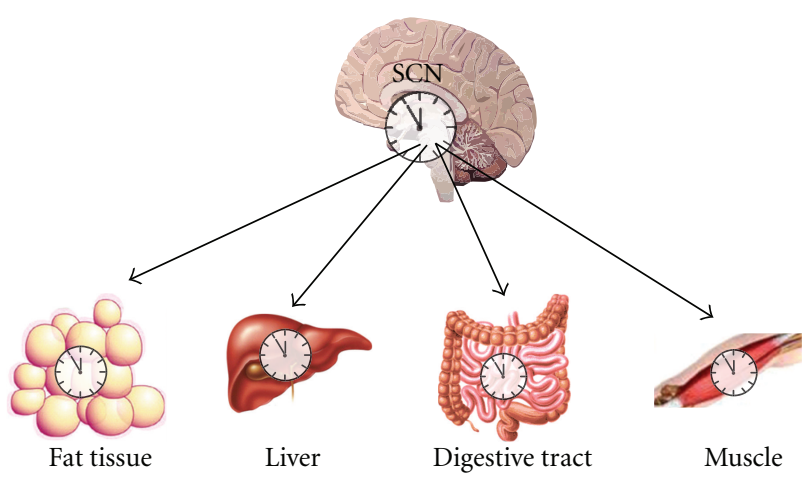

FIGURE 1: Effect of the SCN clock on peripheral clocks. The suprachiasmatic (SCN) clock resets signals in peripheral tissues, such as muscle, fat tissue, digestive tract, and liver.

factors. In turn, SCN rhythms can be altered by neuronal and endocrine inputs [25].

\section{Physiological Effects of Reset versus Disrupted Circadian Rhythms}

Disruption of circadian rhythms has negative effects on physiology. Certain pathologies, such as myocardial infarction, pulmonary edema, hypertensive crises, and asthma and allergic attacks, peak at certain times during the circadian cycle [26-28]. These findings emphasize the prominent influence of the circadian clock on human physiology and pathophysiology [8]. Living in a Western society requires us to extend wakefulness or repeatedly invert the normal sleep-wake cycle, for example, during shift work or transmeridian flights. These usually cause fatigue, disorientation, insomnia, altered nighttime melatonin levels, and hormone-related diseases [29]. Sleep disorders are also associated with impaired functioning of the central circadian clock exacerbating the disruption [8]. Disruption of circadian coordination has also been found to accelerate cancer proneness, malignant growth, and tumor progression [29-31]. Recently, the circadian clock has been linked to energy homeostasis and its disruption leads to metabolic disorders (see below). Thus, disruption of circadian coordination leads to hormone imbalance, sleep disorders, cancer proneness, and reduced life span [8, 29-33], whereas reset circadian rhythms leads to improved health and increased longevity [34-36]. Indeed, longevity in hamsters is decreased with rhythmicity disruption and is increased in old animals given fetal brain implants that restore robust rhythms [34]. Circadian rhythms also change dramatically with the age, including a shift in the phase and decrease in amplitude [20,37-39].

\section{The Molecular Clock}

The circadian clock is a cellular mechanism of gene transcription, translation, and posttranslational modifications [40]. The mechanism itself exists in both the central clock and peripheral tissues. In all tissues, generation of circadian rhythms requires the coexpression of specific clock genes. The mechanism includes several key players. The transcription factor CLOCK dimerizes with BMAL1 to activate transcription upon binding to E-box (5'-CACGTG-3') promoter elements [11]. CLOCK:BMAL1 heterodimer mediates transcription of a large number of genes including Pers and Crys. The PERIOD proteins (PER1, PER2, and PER3) and the two CRYPTOCHROMEs (CRY1 and CRY2) operate as negative regulators [41-43]. When PERs and CRYs are produced, they oligomerize, translocate to the nucleus, and inhibit CLOCK:BMAL1-mediated transcription (Figure 2). In addition, casein kinase I epsilon $(\mathrm{CKI} \varepsilon)$ phosphorylates the PER proteins and, thereby, enhances their instability and degradation [44-46]. CKIE also phosphorylates and partially activates BMAL1 [47].

\section{The Circadian Clock and Metabolic Homeostasis}

The circadian clock regulates metabolism and energy homeostasis in peripheral tissues [2, 48]. The expression and/or activity of certain enzymes and transport systems $[49,50]$ involved in the various metabolic pathways, such as cholesterol metabolism, amino acid regulation, drug and toxin metabolism, the citric acid cycle, and glycogen and glucose metabolism, exhibit circadian expression [2, 48, 51-54]. Similarly, glucose uptake and adenosine triphosphate (ATP) concentrations exhibit circadian fluctuations in brain and peripheral tissues $[52,55,56]$. Indeed, lesions of rat SCN clock abolishes daily changes in glucose homeostasis [57], altering rhythms in glucose utilization rates and hepatic glucose production. This is because the SCN projects to the preautonomic paraventricular nucleus (PVN) neurons that control hepatic glucose production [55].

One of the key tissues that regulate metabolism is the adipose tissue. Circadian clocks have been shown to be present in white and brown adipose tissues $[58,59]$. Adipose tissue secretes metabolic mediators, such as adiponectin, resistin, visfatin, and leptin that are clock controlled [60]. In addition, key metabolic factors in adipocytes exhibit diurnal variations in expression [61]. In addition, many hormones that regulate metabolism, such as insulin [53], glucagon [62], adiponectin [60], corticosterone [63], leptin, and ghrelin [64, 65], exhibit circadian oscillation. Leptin, secreted from adipose tissue, plays an important role in appetite suppression in the brain. Plasma leptin levels are circadian with leptin peaking early in the nonactive phase, that is during the early dark phase in diurnal animals, such as monkeys and humans $[66,67]$, and during the early to mid-light phase in nocturnal animals, such as rats and mice $[68,69]$. Neither feeding time nor adrenalectomy affects the rhythmicity of leptin release. However, ablation of the SCN eliminates leptin circadian rhythmicity in rodents, suggesting that the central circadian clock regulates leptin expression [68]. Leptin receptors are present on SCN neurons [70-72], suggesting that leptin binds directly to SCN neurons. It seems that leptin may affect the central circadian clock directly via its receptors on SCN neurons and/or through its effect on the arcuate nucleus (ARC), 


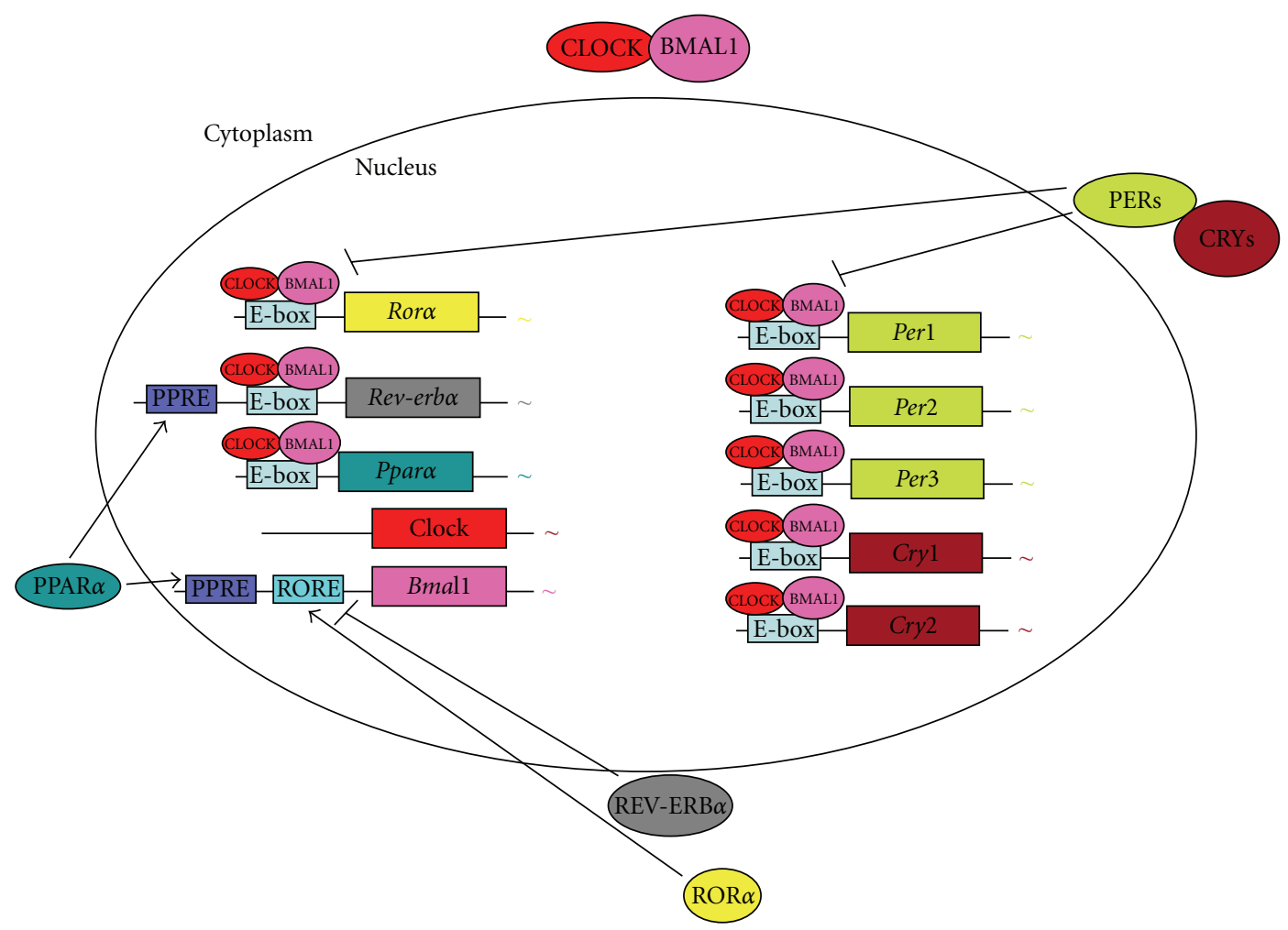

FIGURE 2: The core mechanism of the mammalian circadian clock and its link to energy metabolism. The cellular oscillator is composed of a positive limb (CLOCK and BMAL1) and a negative limb (CRYs and PERs). CLOCK and BMAL1 dimerize in the cytoplasm and translocate to the nucleus. The CLOCK:BMAL1 heterodimer then binds to enhancer (E-box) sequences located in the promoter region of Per and Cry genes, activating their transcription. After translation, PERs and CRYs undergo nuclear translocation and inhibit CLOCK:BMAL1, resulting in decreased transcription of their own genes. CLOCK:BMAL1 heterodimer also induces the transcription of Rev-erb $\alpha$ and Ror $\alpha$. $\mathrm{ROR} \alpha$ and $\mathrm{REV}-\mathrm{ERB} \alpha$ regulate lipid metabolism and adipogenesis, and also participate in the regulation of $B m a l 1$ expression. ROR $\alpha$ stimulates and REV-ERB $\alpha$ inhibits Bmall transcription, acting through RORE. CLOCK:BMAL1 heterodimer also mediates the transcription of Ppar $\alpha$, a nuclear receptor involved in glucose and lipid metabolism. PPAR $\alpha$ activates transcription of Rev-erba by binding to a peroxisome proliferator-response element (PPRE). PPAR $\alpha$ also induces Bmall expression, acting through PPRE located in its promoter.

a region nearby the SCN involved in appetite regulation. These findings place leptin as a major bridge linking energy homeostasis and circadian control.

\section{Circadian Rhythms of Hormone and Metabolic Disorders}

7.1. Insulin. Daily oscillation of insulin secretion and glucose tolerance are lost in patients with type 2 diabetes [73, 74], as are daily variations in plasma corticosterone levels and locomotor activity in streptozotocin-induced diabetic rats $[75,76]$. These results suggest that loss of circadian rhythmicity of glucose metabolism may contribute to the development of metabolic disorders, such as type 2 diabetes [74-78].

7.2. Leptin. In obese subjects, leptin retains diurnal variation in release, but with lower amplitude $[79,80]$. Circadian patterns of leptin concentration were distinctly different between adult women with upper-body or lower-body obesity, with a delay in peak values of leptin of approximately $3 \mathrm{~h}$ in women with upper-body obesity [81].

7.3. Adiponectin. The rhythmic expression of resistin and adiponectin, two cytokines secreted from adipose tissue, was greatly blunted in obese (KK) and obese, diabetic $\left(\mathrm{KK}-\mathrm{A}^{\mathrm{y}}\right)$ mice [60]. In humans, circulating adiponectin levels exhibit both ultradian pulsatility and a diurnal variation. The expression of many adipokines is blunted in obese patients $[68,82,83]$. In obese subjects, adiponectin levels were significantly lower than lean controls, although the obese group had significantly higher average peak of secretion [84].

\section{Mutual Regulation of Key Metabolic Factors and Clock Mechanism}

8.1. BMAL1. Recent molecular studies established the involvement of the activity of the positive circadian transcription factor BMAL1 in the control of adipogenesis and lipid metabolism in mature adipocytes via Wnt signaling pathway $[85,86]$. Embryonic fibroblasts from Bmal1 ${ }^{-/-}$ 
knockout mice failed to differentiate into adipocytes. Loss of BMAL1 expression led to a significant decrease in adipogenesis and gene expression of several key adipogenic/lipogenic factors. Bmal1 $1^{-/-}$mice exhibited a metabolic syndrome-like onset, that is, elevation of the level of circulating fatty acids, including triglycerides, free fatty acids, and low-density lipoprotein (LDL)-cholesterol. In addition, ectopic fat formation was observed in the liver and skeletal muscle. This could be due to loss of the functions of adipose tissue, since ectopic fat formation was not observed in tissue-specific Bmal1 $^{-/-}$mice even under high fat diet [87]. Furthermore, overexpression of BMAL1 in adipocytes increased lipid synthesis activity. Thus, BMAL1, a master regulator of circadian rhythms, plays important roles in the regulation of adipose differentiation and lipogenesis in mature adipocytes [86]. These findings may explain in part why clock disruption leads to obesity. However, recently it was reported that disruption of Bmall, in mice led to increased adipogenesis, adipocyte hypertrophy, and obesity, compared to wild-type mice. Attenuation of Bmall function resulted in downregulation of genes in the canonical Wnt pathway, known to suppress adipogenesis and its overexpression to augmentation [85]. Clearly, BMAL1 plays a role in adipogenesis, however, more studies are merited.

8.2. REV-ERBs and RORs. Two other important families of factors that link the circadian clock with lipid metabolism are the REV-ERB and ROR families. REV-ERBs and RORs, which are crucial for adipocyte differentiation [88], lipogenesis and lipid storage exhibit striking circadian rhythm $[61,89]$. In addition to their role in lipid metabolism and adipocyte differentiation, REV-ERBs are a negative regulator of Bmal1 expression [90, 91]. In contrast, retinoic acidrelated orphan receptor $\alpha(\mathrm{ROR} \alpha)$ is a positive regulator of Bmal1 expression $[92,93]$. In addition, the CLOCK:BMAL1 heterodimer regulates the expression of both Rev-erb $\alpha$ and Ror $[91,92,94]$ (Figure 2). Treatment of diet-induced obese mice with a REV-ERB agonist decreased obesity by reducing fat mass and markedly improving dyslipidaemia and hyperglycaemia [95], suggesting that inhibition of BMAL1 expression is beneficial for obesity (see above).

8.3. PPAR $\alpha$. Peroxisome proliferator-activated receptor $\alpha$ $(\operatorname{PPAR} \alpha)$ is a member of the nuclear receptor family. PPAR $\alpha$ serves also as a link between metabolism and the circadian clock. PPAR $\alpha$ plays a key role in the transcription of genes involved in lipid and glucose metabolism upon binding of endogenous free fatty acids $[96,97]$. Its expression is mediated by the CLOCK:BMAL heterodimer. In turn, PPAR $\alpha$ binds to the peroxisome-proliferator response element (PPRE) to activate Bmal1 expression [4, 98, 99]. We recently showed that a PPAR $\alpha$ agonist advanced locomotor activity and feeding daily rhythms in mice [100].

8.4. PPARy Coactivator (PGC-1 $\alpha$ ). PGC- $1 \alpha$, a transcriptional coactivator that regulates energy metabolism, exhibits circadian expression. In turn, PGC- $1 \alpha$ stimulates the expression of Bmall and Rev-erbo, through coactivation of the
ROR family of orphan nuclear receptors [101, 102]. The role of PGC- $1 \alpha$ in the circadian system is emphasized by null mice that show abnormal diurnal rhythms of activity, body temperature, and metabolic rate, due to aberrant expression of clock genes and those involved in energy metabolism. Indeed, analyses of PGC- $1 \alpha$-deficient fibroblasts and mice with liver-specific knockdown of PGC- $1 \alpha$ indicate that it is required for cell-autonomous clock function [102].

8.5. AMP-Activated Protein Kinase (AMPK). AMPK is a sensor of the energy status within cells, whose activation leads to increased catabolism $[103,104]$. AMPK has been found to directly phosphorylate Ser-389 of CKI $\varepsilon$, resulting in increased CKI $\varepsilon$ activity leading to PERs degradation [105]. AMPK also phosphorylates and, as a result, destabilizes CRY1 in mouse fibroblasts [106]. PERs and CRYs degradation causes the relief of CLOCK:BMAL1-mediated expression leading to a phase advance in the circadian expression in some tissues [107]. Recently, it was shown that metformin, an indirect AMPK activator, leads to phase changes in a tissue-specific manner, mainly phase advances in the liver but phase delays in muscle tissue [108]. The major role of AMPK in the core clock mechanism merits further study.

8.6. SIRT1. Another protein found to link metabolism with the circadian clock is SIRT1, an $\mathrm{NAD}^{+}$-dependent histone deacetylase involved in transcriptional silencing $[109,110]$. It was recently found that AMPK modulates $\mathrm{NAD}^{+}$levels and SIRT1 activity [109]. Nonhistone substrates of SIRT1 include regulatory molecules that modulate energy metabolism, such as PPAR $\gamma$ and PGC- $1 \alpha$ [111], key regulators of the core molecular clock (see above). It turns out that SIRT1 interacts directly with CLOCK and deacetylates BMAL1 and PER2 $[112,113]$ affecting their stability. Deacetylated PER2 is further phosphorylated and degraded relieving the inhibition of CLOCK:BMAL1 heterodimer. CLOCK:BMAL1 heterodimer also regulates the circadian expression of NAMPT (nicotinamide phosphoribosyltransferase), a rate-limiting enzyme in the $\mathrm{NAD}^{+}$salvage pathway. SIRT1 is recruited to the Nampt promoter and contributes to the circadian synthesis of its own coenzyme [114]. In addition, CLOCK and its homolog NPAS2 can bind efficiently to BMAL1 and consequently to E-box sequences in the presence of NADH and NADPH. On the other hand, $\mathrm{NAD}^{+}$and $\mathrm{NADP}^{+}$inhibit DNA binding of CLOCK:BMAL1 or NPAS2:BMAL1 [115, 116]. Thus, the levels of $\mathrm{NAD}^{+}$together with the cycling of SIRT1 can determine the activity and robustness of clock gene transcription.

\section{Clock Mutants and Metabolic Disorders}

Although disruption of circadian expression leads to metabolic disorders, the most compelling linkage between metabolic disorders and the circadian clock is demonstrated by the phenotypes of clock gene mutants and knockouts. 
9.1. Clock. Mice with a truncated exon 18 and deleted exon 19 of the Clock gene (Clock ${ }^{\Delta 19}$ mice) have a greatly attenuated diurnal feeding rhythm, are hyperphagic and obese, and develop a metabolic syndrome of hyperleptinemia, hyperlipidemia, hepatic steatosis, and hyperglycemia [5]. However, some studies found that Clock mutant mice have lower serum triglyceride and free fatty acids than wild-type mice [117]. Combination of the $\operatorname{Clock}^{\Delta 19}$ mutation with the leptin knockout $(o b / o b)$ resulted in significantly heavier mice than the $o b / o b$ phenotype [118], reiterating the contribution of clock disruption to the obese phenotype $[2,11,48]$.

9.2. Bmal1. Bmal1 ${ }^{-1-}$ knockout mice, similarly to Clock mutant mice, exhibited suppressed diurnal variations in glucose and triglycerides as well as abolished gluconeogenesis. Although recovery from insulin-induced hypoglycemia was impaired in Clock mutant and Bmal1 ${ }^{-/-}$knockout mice, the counter-regulatory response of corticosterone and glucagon was retained [119].

9.3. Per2. The diurnal feeding rhythm in Per2 ${ }^{-/-}$mice is absent and these mice exhibit no glucocorticoid rhythm even though the corticosterone response to hypoglycemia is intact. Interestingly, although food consumption was similar during the light and dark periods, Per2 ${ }^{-/}$mice fed a high-fat diet developed significant obesity [120].

\section{Effect of Restricted Feeding (RF) on Circadian Rhythms}

RF limits the time and duration of food availability without calorie reduction, that is, food is provided ad libitum for about $3-5 \mathrm{~h}$ at the same time every day, usually at daytime [40, 49, 121, 122]. Rodents on RF, although nocturnal, adjust to the diurnal feeding period within a few days and learn to eat their daily food intake during that limited time [123125]. Restricting food to a particular time of day has profound effects on the behavior and physiology of animals. Many physiological activities normally dictated by the SCN, such as body temperature, locomotor activity, and heart rate, are altered by RF [126-129]. 2-4 h before the meal, the animals display food anticipatory behavior, which is demonstrated by an increase in locomotor activity, body temperature, corticosterone secretion, gastrointestinal motility, and activity of digestive enzymes [122, 125, 130, 131], all are known output systems of the biological clock. RF is dominant over the SCN and is effective in all lighting conditions including in SCN-lesioned animals [122, 127, 129, 132-134]. RF affects circadian oscillators in peripheral tissues, such as liver, kidney, heart, and pancreas, with no effect on the central pacemaker in the SCN $[40,49,121,127,133,135$, 136]. Thus, RF uncouples the SCN from the periphery, suggesting that nutritional regulation of clock oscillators in peripheral tissues may play a direct role in coordinating metabolic oscillations [137]. As soon as food availability returns to be ad libitum, the SCN clock, whose phase remains unaffected, resets the peripheral oscillators [135]. It has recently been shown that long-term day-time RF can increase the amplitude of clock gene expression, increase expression of catabolic factors, and reduce the levels of disease markers leading to better health [138] (Figure 3). Moreover, timed high-fat diet led to reduced body weight and improved metabolism compared to animals that consumed the same caloric intake spread out throughout the day [139] (see below).

Because timed feeding is dominant in resetting circadian rhythms even in animals with lesioned SCN, it has been suggested that there is a food-entrainable oscillator (FEO). However, the location of this FEO has been elusive. Lesions in brain regions involved in feeding, such as the dorsomedial hypothalamic nucleus (DMH) [140-143], the brain stem parabrachial nuclei (PBN) $[140,144]$, and the core and shell regions of nucleus accumbens $[145,146]$, revealed that these nuclei may be involved in FEO output, but they cannot fully account for the oscillation [147]. Neither vagal signals nor leptin are critical for the entrainment [130, 148]. CLOCK [149] or BMAL1 [150] and other clock genes [151] have been shown not to be necessary for food anticipatory activity. However, it has recently been demonstrated that Per2 mutant mice did not exhibit wheel-running food anticipation [152, 153]. Thus, how RF entrains circadian rhythms remains an extremely important topic for research.

\section{Effect of Calorie Restriction (CR) on Circadian Rhythms}

CR refers to a dietary regimen low in calories without malnutrition. CR restricts the amount of calories derived from carbohydrates, fats, or proteins to $60-75 \%$ of ad libitum-fed animals [154]. It has been documented that calorie restriction significantly extends the life span of rodents by up to $50 \%[155,156]$. In addition to the increase in life span, CR also delays the occurrence of age-associated pathophysiological changes, such as cancer, diabetes, kidney disease, and cataracts [156-159]. Theories on how CR modulates aging and longevity abound, but the exact mechanism is still unknown [156]. As opposed to RF, CR entrains the clock in the SCN [160-163], indicating that calorie reduction could affect the central oscillator. CR during the daytime affects the temporal organization of the SCN clockwork and circadian outputs in mice under light/dark cycle. In addition, CR affects responses of the circadian system to light, indicating that energy metabolism modulates gating of photic inputs in mammals [164]. These findings suggest that synchronization of peripheral oscillators during CR could be achieved directly due to the temporal eating, as has been reported for RF [127, $135,136]$, or by synchronizing the SCN [160-162], which, in turn, sends humoral or neuronal signals to synchronize the peripheral tissues [107, 165] (Figure 3).

\section{Effect of Intermittent Fasting (IF) on Circadian Rhythms}

During IF, food is available ad libitum every other day. IF-treated mice eat on the days they have access to food 


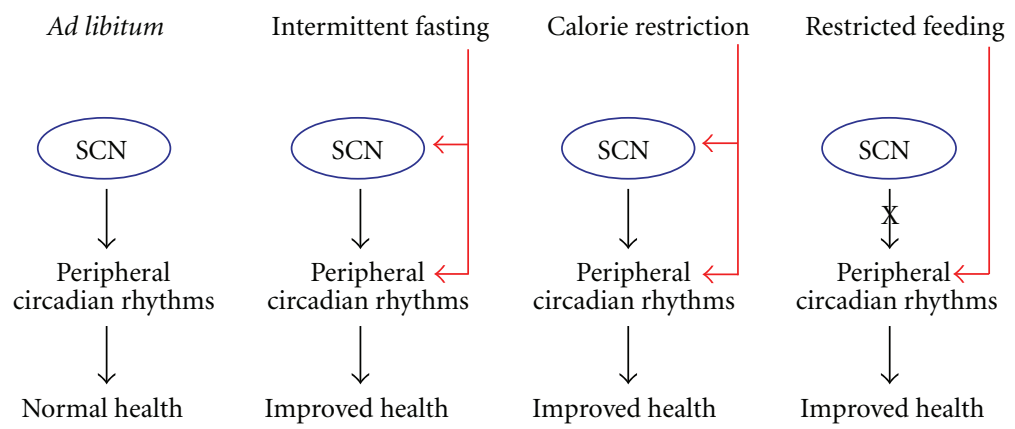

FIGURE 3: Effect of feeding regimens on circadian rhythms and health. SCN: suprachiasmatic nuclei.

approximately twice as much as those having continuous access to food $[166,167]$. Similarly to calorically restricted animals, IF-fed animals exhibit increased life span in comparison with the ad libitum-fed control [168] as well as improved glucose metabolism, cardioprotection, neuroprotection $[166,169-173]$, and increased resistance to cancer [167]. The IF-induced beneficial effects are thought to occur independently of the overall caloric intake, but the underlying mechanisms are still unknown. One suggested mechanism is stimulation of cellular stress pathways induced by the IF regimen $[166,174,175]$. Recently it has been shown that when food was introduced during the light period, mice exhibited almost arrhythmicity in clock gene expression in the liver. Unlike daytime feeding, nighttime feeding yielded rhythms similar to those generated during ad libitum feeding [176]. The fact that IF can affect circadian rhythms differently depending on the timing of food availability suggests that this regimen affects the SCN clock, similarly to CR. SCN resetting by IF and CR could be involved in the health benefits conferred by these regimens [107] (Figure 3).

\section{Effect of High-Fat Diet on Circadian Rhythms}

Few studies show that a high-fat diet leads to minimal effects on the rhythmic expression of clock genes in visceral adipose tissue and liver [177]. However, recent studies have shown that introduction of a high-fat diet to animals leads to rapid changes in both the period of locomotor activity in constant darkness and to increased food intake during the normal rest period under light-dark conditions [178]. These changes in behavioral rhythmicity correlated with disrupted clock gene expression within hypothalamus, liver, and adipose tissue, and as well as with altered cycling of hormones and nuclear hormone receptors involved in fuel utilization, such as leptin, thyroid stimulating hormone (TSH), and testosterone in mice, rats, and humans [178-183]. Furthermore, a high-fat diet modulates carbohydrate metabolism by amplifying circadian variation in glucose tolerance and insulin sensitivity [119].

In addition to the disruption of clock gene expression, high-fat diet induced a phase delay in clock and clockcontrolled genes $[179,180]$. As mentioned above, AMPK activation leads to CKI $\varepsilon$ activity, degradation of PERs, and to a phase advance. As the levels of AMPK decline under HF diet $[179,180]$, it is plausible that the changes seen in the expression phase of genes under HF diet are mediated by changes in AMPK levels. In addition to its effect on gene expression, high-fat feeding led to impaired adjustment to local time by light resetting, including slower rate of reentrainment of behavioral and body temperature rhythms after "jet-lag" tests (6h advanced light-dark cycle) and reduced phase-advance responses to light. These results correlated with reduction in c-FOS and phosphor-ERK expression in the SCN in response to light-induced phase shifts [184].

Recently, it was shown that timed high-fat diet can prevent obesity $[139,185]$. Timed HF diet led to decreased body weight, cholesterol and TNF $\alpha$ levels and improved insulin sensitivity compared with mice fed HF diet ad libitum. Timed HF-fed mice exhibited a better satiated and less stressed phenotype of low ghrelin and corticosterone compared with mice fed timed low-fat diet [139]. In addition, timed HF diet improved metabolic pathway function and oscillations of the circadian clock and their target gene expression. These changes in catabolic and anabolic pathways altered liver metabolome and improved nutrient utilization and energy expenditure [185]. Altogether, these findings suggest that timing can prevent obesity and rectify the harmful effects of HF diet.

\section{Conclusion}

(i) Western lifestyle leads to high food consumption, inactivity during the active period, enhanced activity in the rest period, and shortened sleep period.

(ii) Disrupted biological rhythms might lead to attenuated circadian feeding rhythms, disrupted metabolism, cancer proneness, and reduced life expectancy.

(iii) Resetting the biological clock by food or feeding time may lead to better functionality of physiological systems, preventing metabolic disorders, promoting well being, and extending life span.

(iv) Feeding time has the ability to reset bodily rhythms. 


\section{References}

[1] S. B. Wyatt, K. P. Winters, and P. M. Dubbert, "Overweight and obesity: prevalence, consequences, and causes of a growing public health problem," American Journal of the Medical Sciences, vol. 331, no. 4, pp. 166-174, 2006.

[2] O. Froy, "Metabolism and circadian rhythms - implications for obesity," Endocrine Reviews, vol. 31, no. 1, pp. 1-24, 2010.

[3] B. Marcheva, K. M. Ramsey, E. D. Buhr et al., "Disruption of the clock components CLOCK and BMAL1 leads to hypoinsulinaemia and diabetes," Nature, vol. 466, no. 7306, pp. 627-631, 2010.

[4] K. Oishi, H. Shirai, and N. Ishida, "CLOCK is involved in the circadian transactivation of peroxisome- proliferatoractivated receptor $\alpha(\operatorname{PPAR} \alpha)$ in mice," Biochemical Journal, vol. 386, no. 3, pp. 575-581, 2005.

[5] F. W. Turek, C. Joshu, A. Kohsaka et al., "Obesity and metabolic syndrome in circadian clock mutant nice," Science, vol. 308, no. 5724, pp. 1043-1045, 2005.

[6] D. M. Arble, J. Bass, A. D. Laposky, M. H. Vitaterna, and F. W. Turek, "Circadian timing of food intake contributes to weight gain,” Obesity, vol. 17, no. 11, pp. 2100-2102, 2009.

[7] S. Panda, J. B. Hogenesch, and S. A. Kay, "Circadian rhythms from flies to human,” Nature, vol. 417, no. 6886, pp. 329-335, 2002.

[8] S. M. Reppert and D. R. Weaver, "Coordination of circadian timing in mammals," Nature, vol. 418, no. 6901, pp. 935-941, 2002.

[9] R. A. Akhtar, A. B. Reddy, E. S. Maywood et al., "Circadian cycling of the mouse liver transcriptome, as revealed by cDNA microarray, is driven by the suprachiasmatic nucleus," Current Biology, vol. 12, no. 7, pp. 540-550, 2002.

[10] G. E. Duffield, J. D. Best, B. H. Meurers, A. Bittner, J. J. Loros, and J. C. Dunlap, "Circadian programs of transcriptional activation, signaling, and protein turnover revealed by microarray analysis of mammalian cells," Current Biology, vol. 12, no. 7, pp. 551-557, 2002.

[11] C. B. Green, J. S. Takahashi, and J. Bass, "The meter of metabolism," Cell, vol. 134, no. 5, pp. 728-742, 2008.

[12] B. Kornmann, N. Preitner, D. Rifat, F. Fleury-Olela, and U. Schibler, "Analysis of circadian liver gene expression by ADDER, a highly sensitive method for the display of differentially expressed mRNAs," Nucleic Acids Research, vol. 29, no. 11, article E51, 2001.

[13] K. F. Storch, O. Lipan, I. Leykin et al., "Extensive and divergent circadian gene expression in liver and heart," Nature, vol. 417, pp. 78-83, 2002.

[14] E. D. Herzog, J. S. Takahashi, and G. D. Block, "Clock controls circadian period in isolated suprachiasmatic nucleus neurons," Nature Neuroscience, vol. 1, no. 8, pp. 708-713, 1998.

[15] C. Liu, D. R. Weaver, S. H. Strogatz, and S. M. Reppert, “Cellular construction of a circadian clock: period determination in the suprachiasmatic nuclei," Cell, vol. 91, no. 6, pp. 855860, 1997.

[16] D. K. Welsh, D. E. Logothetis, M. Meister, and S. M. Reppert, "Individual neurons dissociated from rat suprachiasmatic nucleus express independently phased circadian firing rhythms," Neuron, vol. 14, no. 4, pp. 697-706, 1995.

[17] J. J. Gooley, J. Lu, T. C. Chou, T. E. Scammell, and C. B. Saper, "Melanopsin in cells of origin of the retinohypothalamic tract," Nature Neuroscience, vol. 4, no. 12, p. 1165, 2001.

[18] R. J. Lucas, M. S. Freedman, D. Lupi, M. Munoz, Z. K. DavidGray, and R. G. Foster, "Identifying the photoreceptive inputs to the mammalian circadian system using transgenic and retinally degenerate mice," Behavioural Brain Research, vol. 125, no. 1-2, pp. 97-102, 2001.

[19] J. E. Quintero, S. J. Kuhlman, and D. G. McMahon, "The biological clock nucleus: a multiphasic oscillator network regulated by light," Journal of Neuroscience, vol. 23, no. 22, pp. 8070-8076, 2003.

[20] O. Froy, "Circadian rhythms, aging, and life span in mammals," Physiology (Bethesda), vol. 26, pp. 225-235, 2011.

[21] O. Froy and N. Chapnik, "Circadian oscillation of innate immunity components in mouse small intestine," Molecular Immunology, vol. 44, no. 8, pp. 1954-1960, 2007.

[22] C. Lee, J. P. Etchegaray, F. R. A. Cagampang, A. S. I. Loudon, and S. M. Reppert, "Posttranslational mechanisms regulate the mammalian circadian clock," Cell, vol. 107, no. 7, pp. 855-867, 2001.

[23] D. K. Welsh, S. H. Yoo, A. C. Liu, J. S. Takahashi, and S. A. Kay, "Bioluminescence imaging of individual fibroblasts reveals persistent, independently phased circadian rhythms of clock gene expression," Current Biology, vol. 14, no. 24, pp. 2289-2295, 2004.

[24] S. H. Yoo, S. Yamazaki, P. L. Lowrey et al., "PERIOD2::LUCIFERASE real-time reporting of circadian dynamics reveals persistent circadian oscillations in mouse peripheral tissues," Proceedings of the National Academy of Sciences of the United States of America, vol. 101, no. 15, pp. 5339-5346, 2004.

[25] K. Saeb-Parsy, S. Lombardelli, F. Z. Khan, K. McDowall, I. T. H. Au-Yong, and R. E. J. Dyball, "Neural connections of hypothalamic neuroendocrine nuclei in the rat," Journal of Neuroendocrinology, vol. 12, no. 7, pp. 635-648, 2000.

[26] N. Burioka, Y. Fukuoka, M. Takata et al., "Circadian rhythms in the CNS and peripheral clock disorders: function of clock genes: influence of medication for bronchial asthma on circadian gene," Journal of Pharmacological Sciences, vol. 103, no. 2, pp. 144-149, 2007.

[27] B. J. Maron, J. Kogan, M. A. Proschan, G. M. Hecht, and W. C. Roberts, "Circadian variability in the occurrence of sudden cardiac death in patients with hypertrophic cardiomyopathy," Journal of the American College of Cardiology, vol. 23, no. 6, pp. 1405-1409, 1994.

[28] B. Staels, "When the Clock stops ticking, metabolic syndrome explodes," Nature Medicine, vol. 12, no. 1, pp. 54-55, 2006.

[29] S. Davis and D. K. Mirick, "Circadian disruption, shift work and the risk of cancer: a summary of the evidence and studies in Seattle," Cancer Causes and Control, vol. 17, no. 4, pp. 539545, 2006.

[30] E. Filipski, V. M. King, X. M. Li et al., "Disruption of circadian coordination accelerates malignant growth in mice," Pathologie Biologie, vol. 51, no. 4, pp. 216-219, 2003.

[31] L. Fu, H. Pelicano, J. Liu, P. Huang, and C. C. Lee, "The circadian gene period2 plays an important role in tumor suppression and DNA-damage response in vivo," Cell, vol. 111, pp. 41-50, 2002.

[32] R. V. Kondratov, A. A. Kondratova, V. Y. Gorbacheva, O. V. Vykhovanets, and M. P. Antoch, "Early aging and age-related pathologies in mice deficient in BMAL1, the core component of the circadian clock," Genes and Development, vol. 20, no. 14, pp. 1868-1873, 2006.

[33] P. D. Penev, D. E. Kolker, P. C. Zee, and F. W. Turek, "Chronic circadian desynchronization decreases the survival of animals with cardiomyopathic heart disease," American Journal of Physiology, vol. 275, no. 6, pp. H2334-H2337, 1998. 
[34] M. W. Hurd and M. R. Ralph, "The significance of circadian organization for longevity in the golden hamster," Journal of Biological Rhythms, vol. 13, no. 5, pp. 430-436, 1998.

[35] M. Karasek, "Melatonin, human aging, and age-related diseases," Experimental Gerontology, vol. 39, no. 11-12, pp. 1723-1729, 2004.

[36] A. Klarsfeld and F. Rouyer, "Effects of circadian mutations and LD periodicity on the life span of drosophila melanogaster," Journal of Biological Rhythms, vol. 13, no. 6, pp. 471-478, 1998.

[37] M. A. Hofman and D. F. Swaab, "Living by the clock: the circadian pacemaker in older people," Ageing Research Reviews, vol. 5, no. 1, pp. 33-51, 2006.

[38] K. Scarbrough, S. Losee-Olson, E. P. Wallen, and F. W. Turek, "Aging and photoperiod affect entrainment and quantitative aspects of locomotor behavior in Syrian hamsters," American Journal of Physiology, vol. 272, no. 4, pp. R1219-R1225, 1997.

[39] S. Yamazaki, M. Straume, H. Tei, Y. Sakaki, M. Menaker, and G. D. Block, "Effects of aging on central and peripheral mammalian clocks," Proceedings of the National Academy of Sciences of the United States of America, vol. 99, no. 16, pp. 10801-10806, 2002.

[40] U. Schibler, J. Ripperger, and S. A. Brown, "Peripheral circadian oscillators in mammals: time and food," Journal of Biological Rhythms, vol. 18, no. 3, pp. 250-260, 2003.

[41] O. Froy, D. C. Chang, and S. M. Reppert, "Redox potential: differential roles in dCRY and mCRY1 functions," Current Biology, vol. 12, no. 2, pp. 147-152, 2002.

[42] S. M. Reppert and D. R. Weaver, "Molecular analysis of mammalian circadian rhythms," Annual Review of Physiology, vol. 63, pp. 647-676, 2001.

[43] M. J. Zylka, L. P. Shearman, D. R. Weaver, and S. M. Reppert, "Three period homologs in mammals: differential light responses in the suprachiasmatic circadian clock and oscillating transcripts outside of brain," Neuron, vol. 20, no. 6, pp. 1103-1110, 1998.

[44] E. J. Eide and D. M. Virshup, "Casein kinase I: another cog in the circadian clockworks," Chronobiology International, vol. 18, no. 3, pp. 389-398, 2001.

[45] E. J. Eide, M. F. Woolf, H. Kang et al., "Control of mammalian circadian rhythm by CKIE-regulated proteasome-mediated PER2 degradation," Molecular and Cellular Biology, vol. 25, no. 7, pp. 2795-2807, 2005.

[46] D. Whitmore, N. Cermakian, C. Crosio et al., "A clockwork organ," Biological Chemistry, vol. 381, no. 9-10, pp. 793-800, 2000.

[47] E. J. Eide, H. Kang, S. Crapo, M. Gallego, and D. M. Virshup, "Casein kinase I in the mammalian circadian clock," Methods in Enzymology, vol. 393, article no. 19, pp. 408-418, 2005.

[48] M. Garaulet and J. A. Madrid, "Chronobiological aspects of nutrition, metabolic syndrome and obesity," Advanced Drug Delivery Reviews, vol. 62, no. 9-10, pp. 967-978, 2010.

[49] T. Hirota and Y. Fukada, "Resetting mechanism of central and peripheral circadian clocks in mammals," Zoological Science, vol. 21, no. 4, pp. 359-368, 2004.

[50] A. Kohsaka and J. Bass, "A sense of time: how molecular clocks organize metabolism," Trends in Endocrinology and Metabolism, vol. 18, no. 1, pp. 4-11, 2007.

[51] A. J. Davidson, O. Castañón-Cervantes, and F. K. Stephan, "Daily oscillations in liver function: diurnal vs circadian rhythmicity," Liver International, vol. 24, no. 3, pp. 179-186, 2004.
[52] S. E. la Fleur, "Daily rhythms in glucose metabolism: suprachiasmatic nucleus output to peripheral tissue," Journal of Neuroendocrinology, vol. 15, no. 3, pp. 315-322, 2003.

[53] S. E. La Fleur, A. Kalsbeek, J. Wortel, and R. M. Buijs, "A suprachiasmatic nucleus generated rhythm in basal glucose concentrations," Journal of Neuroendocrinology, vol. 11, no. 8, pp. 643-652, 1999.

[54] K. M. Ramsey, B. Marcheva, A. Kohsaka, and J. Bass, "The clockwork of metabolism," Annual Review of Nutrition, vol. 27, pp. 219-240, 2007.

[55] A. Kalsbeek, M. Ruiter, S. E. La Fleur, C. Cailotto, F. Kreier, and R. M. Buijs, "Chapter 17: the hypothalamic clock and its control of glucose homeostasis," Progress in Brain Research, vol. 153, pp. 283-307, 2006.

[56] S. Yamazaki, Y. Ishida, and S. I. Inouye, "Circadian rhythms of adenosine triphosphate contents in the suprachiasmatic nucleus, anterior hypothalamic area and caudate putamen of the rat-negative correlation with electrical activity," Brain Research, vol. 664, no. 1-2, pp. 237-240, 1994.

[57] C. Cailotto, S. E. La Fleur, C. Van Heijningen et al., "The suprachiasmatic nucleus controls the daily variation of plasma glucose via the autonomic output to the liver: are the clock genes involved?" European Journal of Neuroscience, vol. 22, no. 10, pp. 2531-2540, 2005.

[58] S. Zvonic, Z. E. Floyd, R. L. Mynatt, and J. M. Gimble, "Circadian rhythms and the regulation of metabolic tissue function and energy homeostasis," Obesity, vol. 15, no. 3, pp. 539-543, 2007.

[59] S. Zvonic, A. A. Ptitsyn, S. A. Conrad et al., "Characterization of peripheral circadian clocks in adipose tissues," Diabetes, vol. 55, no. 4, pp. 962-970, 2006.

[60] H. Ando, H. Yanagihara, Y. Hayashi et al., "Rhythmic messenger ribonucleic acid expression of clock genes and adipocytokines in mouse visceral adipose tissue," Endocrinology, vol. 146, no. 12, pp. 5631-5636, 2005.

[61] M. S. Bray and M. E. Young, "Circadian rhythms in the development of obesity: potential role for the circadian clock within the adipocyte," Obesity Reviews, vol. 8, no. 2, pp. 169$181,2007$.

[62] M. Ruiter, S. E. La Fleur, C. Van Heijningen, J. Van der Vliet, A. Kalsbeek, and R. M. Buijs, "The daily rhythm in plasma glucagon concentrations in the rat is modulated by the biological clock and by feeding behavior," Diabetes, vol. 52, no. 7, pp. 1709-1715, 2003.

[63] S. F. De Boer and J. Van Der Gugten, "Daily variations in plasma noradrenaline, adrenaline and corticosterone concentrations in rats," Physiology and Behavior, vol. 40, no. 3, pp. 323-328, 1987.

[64] R. S. Ahima, D. Prabakaran, and J. S. Flier, "Postnatal leptin surge and regulation of circadian rhythm of leptin by feeding: implications for energy homeostasis and neuroendocrine function," Journal of Clinical Investigation, vol. 101, no. 5, pp. 1020-1027, 1998.

[65] B. Bodosi, J. Gardi, I. Hajdu, E. Szentirmai, F. Obal Jr., and J. M. Krueger, "Rhythms of ghrelin, leptin, and sleep in rats: effects of the normal diurnal cycle, restricted feeding, and sleep deprivation," American Journal of Physiology, vol. 287, no. 5, pp. R1071-R1079, 2004.

[66] J. L. Downs and H. F. Urbanski, "Aging-related sexdependent loss of the circulating leptin 24-h rhythm in the rhesus monkey," Journal of Endocrinology, vol. 190, no. 1, pp. 117-127, 2006.

[67] S. P. Kalra, M. Bagnasco, E. E. Otukonyong, M. G. Dube, and P. S. Kalra, "Rhythmic, reciprocal ghrelin and leptin 
signaling: new insight in the development of obesity," Regulatory Peptides, vol. 111, no. 1-3, pp. 1-11, 2003.

[68] A. Kalsbeek, E. Fliers, J. A. Romijn et al., "The suprachiasmatic nucleus generates the diurnal changes in plasma leptin levels," Endocrinology, vol. 142, no. 6, pp. 2677-2685, 2001.

[69] S. Sukumaran, R. R. Almon, D. C. DuBois, and W. J. Jusko, "Circadian rhythms in gene expression: relationship to physiology, disease, drug disposition and drug action," Advanced Drug Delivery Reviews, vol. 62, no. 9-10, pp. 904 917, 2010.

[70] X. M. Guan, J. F. Hess, H. Yu, P. J. Hey, and L. H. T. Van Der Ploeg, "Differential expression of mRNA for leptin receptor isoforms in the rat brain," Molecular and Cellular Endocrinology, vol. 133, no. 1, pp. 1-7, 1997.

[71] C. X. Yi, J. Van Der Vliet, J. Dai, G. Yin, L. Ru, and R. M. Buijs, "Ventromedial arcuate nucleus communicates peripheral metabolic information to the suprachiasmatic nucleus," Endocrinology, vol. 147, no. 1, pp. 283-294, 2006.

[72] J. M. Zigman, J. E. Jones, C. E. Lee, C. B. Saper, and J. K. Elmquist, "Expression of ghrelin receptor mRNA in the rat and the mouse brain," Journal of Comparative Neurology, vol. 494, no. 3, pp. 528-548, 2006.

[73] G. Boden, X. Chen, and M. Polansky, "Disruption of circadian insulin secretion is associated with reduced glucose uptake in first-degree relatives of patients with type 2 diabetes," Diabetes, vol. 48, no. 11, pp. 2182-2188, 1999.

[74] E. Van Cauter, K. S. Polonsky, and A. J. Scheen, "Roles of circadian rhythmicity and sleep in human glucose regulation," Endocrine Reviews, vol. 18, no. 5, pp. 716-738, 1997.

[75] M. H. Oster, T. W. Castonguay, C. L. Keen, and J. S. Stern, "Circadian rhythm of corticosterone in diabetic rats," Life Sciences, vol. 43, no. 20, pp. 1643-1645, 1988.

[76] A. Velasco, I. Huerta, and B. Marin, "Plasma corticosterone, motor activity and metabolic circadian patterns in streptozotocin-induced diabetic rats," Chronobiology International, vol. 5, no. 2, pp. 127-135, 1988.

[77] Y. Shimomura, M. Takahashi, H. Shimizu et al., "Abnormal feeding behavior and insulin replacement in STZ-induced diabetic rats," Physiology and Behavior, vol. 47, no. 4, pp. 731734, 1990.

[78] V. Spallone, L. Bernardi, L. Ricordi et al., "Relationship between the circadian rhythms of blood pressure and sympathovagal balance in diabetic autonomic neuropathy," Diabetes, vol. 42, no. 12, pp. 1745-1752, 1993.

[79] R. Heptulla, A. Smitten, B. Teague, W. V. Tamborlane, Y. Z. $\mathrm{Ma}$, and S. Caprio, "Temporal patterns of circulating leptin levels in lean and obese adolescents: relationships to insulin, growth hormone, and free fatty acids rhythmicity," Journal of Clinical Endocrinology and Metabolism, vol. 86, no. 1, pp. 90-96, 2001.

[80] J. Licinio, "Longitudinally sampled human plasma leptin and cortisol concentrations are inversely correlated," Journal of Clinical Endocrinology and Metabolism, vol. 83, no. 3, p. 1042, 1998.

[81] F. Perfetto, R. Tarquini, G. Cornélissen et al., "Circadian phase difference of leptin in android versus gynoid obesity," Peptides, vol. 25, no. 8, pp. 1297-1306, 2004.

[82] M. F. Saad, M. G. Riad-Gabriel, A. Khan et al., "Diurnal and ultradian rhythmicity of plasma leptin: effects of gender and adiposity," The Journal of Clinical Endocrinology \& Metabolism, vol. 83 no. 2, pp. 453-459, 1998.

[83] A. Gavrila, C. K. Peng, J. L. Chan, J. E. Mietus, A. L. Goldberger, and C. S. Mantzoros, "Diurnal and ultradian dynamics of serum adiponectin in healthy men: comparison with leptin, circulating soluble leptin receptor, and cortisol patterns," The Journal of Clinical Endocrinology \& Metabolism, vol. 88 no. 6, pp. 2838-2843, 2003.

[84] B. O. Yildiz, M. A. Suchard, M. L. Wong, S. M. McCann, and J. Licinio, "Alterations in the dynamics of circulating ghrelin, adiponectin, and leptin in human obesity," Proceedings of the National Academy of Sciences of the United States of America, vol. 101, no. 28, pp. 10434-10439, 2004.

[85] B. Guo, S. Chatterjee, L. Li et al., "The clock gene, brain and muscle Arnt-like 1, regulates adipogenesis via Wnt signaling pathway," FASEB Journal, vol. 26, pp. 3453-3463, 2012.

[86] S. Shimba, N. Ishii, Y. Ohta et al., "Brain and muscle Arntlike protein-1 (BMAL1), a component of the molecular clock, regulates adipogenesis," Proceedings of the National Academy of Sciences of the United States of America, vol. 102, no. 34, pp. 12071-12076, 2005.

[87] S. Shimba, T. Ogawa, S. Hitosugi et al., "Deficient of a clock gene, brain and muscle Arnt-like protein-1 (BMAL1), induces dyslipidemia and ectopic fat formation," PLoS One, vol. 6, article e25231, 2011.

[88] A. Chawla and M. A. Lazar, "Induction of Rev-ErbA $\alpha$, an orphan receptor encoded on the opposite strand of the $\alpha$-thyroid hormone receptor gene, during adipocyte differentiation," Journal of Biological Chemistry, vol. 268, no. 22, pp. 16265-16269, 1993.

[89] I. P. Torra, V. Tsibulsky, F. Delaunay et al., "Circadian and glucocorticoid regulation of Rev-erb $\alpha$ expression in liver," Endocrinology, vol. 141, no. 10, pp. 3799-3806, 2000.

[90] H. Cho, X. Zhao, M. Hatori et al., "Regulation of circadian behaviour and metabolism by REV-ERB-alpha and REVERB-beta," Nature, vol. 485, pp. 123-127, 2012.

[91] N. Preitner, F. Damiola, Luis-Lopez-Molina et al., "The orphan nuclear receptor REV-ERB $\alpha$ controls circadian transcription within the positive limb of the mammalian circadian oscillator," Cell, vol. 110, no. 2, pp. 251-260, 2002.

[92] T. K. Sato, S. Panda, L. J. Miraglia et al., "A functional genomics strategy reveals Rora as a component of the mammalian circadian clock," Neuron, vol. 43, no. 4, pp. 527537, 2004.

[93] P. Lau, S. J. Nixon, R. G. Parton, and G. E. Muscat, "RORalpha regulates the expression of genes involved in lipid homeostasis in skeletal muscle cells: caveolin-3 and CPT-1 are direct targets of ROR," The Journal of Biological Chemistry, vol. 279, no. 35, pp. 36828-36840, 2004.

[94] H. R. Ueda, W. Chen, A. Adachi et al., "A transcription factor response element for gene expression during circadian night," Nature, vol. 418, no. 6897, pp. 534-539, 2002.

[95] L. A. Solt, Y. Wang, S. Banerjee et al., "Regulation of circadian behaviour and metabolism by synthetic REV-ERB agonists," Nature, vol. 485, pp. 62-68, 2012.

[96] S. Kersten, B. Desvergne, and W. Wahli, "Roles of PPARS in health and disease," Nature, vol. 405, no. 6785, pp. 421-424, 2000.

[97] P. Lefebvre, G. Chinetti, J. C. Fruchart, and B. Staels, "Sorting out the roles of PPAR $\alpha$ in energy metabolism and vascular homeostasis," Journal of Clinical Investigation, vol. 116, no. 3, pp. 571-580, 2006.

[98] L. Canaple, J. Rambaud, O. Dkhissi-Benyahya et al., "Reciprocal regulation of brain and muscle Arnt-like protein 1 and peroxisome proliferator-activated receptor $\alpha$ defines a novel positive feedback loop in the rodent liver circadian clock," Molecular Endocrinology, vol. 20, no. 8, pp. 1715-1727, 2006. 
[99] I. Inoue, Y. Shinoda, M. Ikeda et al., "CLOCK/BMAL1 is involved in lipid metabolism via transactivation of the peroxisome proliferator-activated receptor (PPAR) response element," Journal of Atherosclerosis and Thrombosis, vol. 12, no. 3, pp. 169-174, 2005.

[100] R. Gutman, M. Barnea, L. Haviv, N. Chapnik, and O. Froy, "Peroxisome proliferator-activated receptor alpha (PPARalpha) activation advances locomotor activity and feeding daily rhythms in mice," International Journal of Obesity, vol. 36, pp. 1131-1134, 2012.

[101] B. Grimaldi and P. Sassone-Corsi, "Circadian rhythms: metabolic clockwork," Nature, vol. 447, no. 7143, pp. 386 387, 2007.

[102] C. Liu, S. Li, T. Liu, J. Borjigin, and J. D. Lin, “Transcriptional coactivator PGC- $1 \alpha$ integrates the mammalian clock and energy metabolism," Nature, vol. 447, no. 7143, pp. 477-481, 2007.

[103] D. Carling, "AMP-activated protein kinase: balancing the scales," Biochimie, vol. 87, no. 1, pp. 87-91, 2005.

[104] D. G. Hardie, S. A. Hawley, and J. W. Scott, "AMP-activated protein kinase-development of the energy sensor concept," Journal of Physiology, vol. 574, no. 1, pp. 7-15, 2006.

[105] H. U. Jee, S. Yang, S. Yamazaki et al., "Activation of 5' -AMPactivated kinase with diabetes drug metformin induces casein kinase $\mathrm{I} \varepsilon(\mathrm{CKI} \varepsilon)$-dependent degradation of clock protein mPer2," Journal of Biological Chemistry, vol. 282, no. 29, pp. 20794-20798, 2007.

[106] K. A. Lamia, U. M. Sachdeva, L. Di Tacchio et al., "AMPK regulates the circadian clock by cryptochrome phosphorylation and degradation," Science, vol. 326, no. 5951, pp. 437-440, 2009.

[107] O. Froy and R. Miskin, "Effect of feeding regimens on circadian rhythms: implications for aging and longevity," Aging, vol. 2, no. 1, pp. 7-27, 2010.

[108] M. Barnea, L. Haviv, R. Gutman, N. Chapnik, Z. Madar, and O. Froy, "Metformin affects the circadian clock and metabolic rhythms in a tissue-specific manner," Biochim Biophys Acta, vol. 1822, pp. 1796-1180, 2012.

[109] C. Canto and J. Auwerx, "Caloric restriction, SIRT1 and longevity," Trends in Endocrinology and Metabolism, vol. 20, no. 7, pp. 325-331, 2009.

[110] M. C. Haigis and L. P. Guarente, "Mammalian sirtuinsemerging roles in physiology, aging, and calorie restriction," Genes and Development, vol. 20, no. 21, pp. 2913-2921, 2006.

[111] C. Cantó, Z. Gerhart-Hines, J. N. Feige et al., "AMPK regulates energy expenditure by modulating $\mathrm{NAD}^{+}$metabolism and SIRT1 activity," Nature, vol. 458, no. 7241, pp. 10561060, 2009.

[112] G. Asher, D. Gatfield, M. Stratmann et al., "SIRT1 regulates circadian clock gene expression through PER2 deacetylation," Cell, vol. 134, no. 2, pp. 317-328, 2008.

[113] Y. Nakahata, M. Kaluzova, B. Grimaldi et al., "The NAD ${ }^{+}$ dependent deacetylase SIRT1 modulates CLOCK-mediated chromatin remodeling and circadian control," Cell, vol. 134, no. 2, pp. 329-340, 2008.

[114] Y. Nakahata, S. Sahar, G. Astarita, M. Kaluzova, and P. Sassone-Corsi, "Circadian control of the $\mathrm{NAD}^{+}$salvage pathway by CLOCK-SIRT1,” Science, vol. 324, no. 5927, pp. 654-657, 2009.

[115] J. Rutter, M. Reick, L. C. Wu, and S. L. McKnight, "Regulation of clock and NPAS2 DNA binding by the redox state of NAD cofactors," Science, vol. 293, no. 5529, pp. 510-514, 2001.
[116] J. Rutter, M. Reick, and S. L. McKnight, "Metabolism and the control of circadian rhythms," Annual Review of Biochemistry, vol. 71, pp. 307-331, 2002.

[117] K. Oishi, G. I. Atsumi, S. Sugiyama et al., "Disrupted fat absorption attenuates obesity induced by a high-fat diet in Clock mutant mice," FEBS Letters, vol. 580, no. 1, pp. 127130, 2006.

[118] K. Oishi, N. Ohkura, M. Wakabayashi et al., "CLOCK is involved in obesity-induced disordered fibrinolysis in ob/ob mice by regulating PAI-1 gene expression," Journal of Thrombosis and Haemostasis, vol. 4, no. 8, pp. 1774-1780, 2006.

[119] R. D. Rudic, P. McNamara, A. M. Curtis et al., "BMAL1 and CLOCK, two essential components of the circadian clock, are involved in glucose homeostasis," PLoS Biology, vol. 2, no. 11, article e377, 2004.

[120] S. Yang, A. Liu, A. Weidenhammer et al., "The role of $m$ Per 2 clock gene in glucocorticoid and feeding rhythms," Endocrinology, vol. 150, no. 5, pp. 2153-2160, 2009.

[121] V. M. Cassone and F. K. Stephan, "Central and peripheral regulation of feeding and nutrition by the mammalian circadian clock: implications for nutrition during manned space flight," Nutrition, vol. 18, no. 10, pp. 814-819, 2002.

[122] F. K. Stephan, "The "other" circadian system: food as a Zeitgeber," Journal of Biological Rhythms, vol. 17, no. 4, pp. 284-292, 2002.

[123] O. Froy, N. Chapnik, and R. Miskin, "Long-lived $\alpha$ MUPA transgenic mice exhibit pronounced circadian rhythms," American Journal of Physiology, vol. 291, no. 5, pp. E1017E1024, 2006.

[124] B. Grasl-Kraupp, W. Bursch, B. Ruttkay-Nedecky, A. Wagner, B. Lauer, and R. Schulte-Hermann, "Food restriction eliminates preneoplastic cells through apoptosis and antagonizes carcinogenesis in rat liver," Proceedings of the National Academy of Sciences of the United States of America, vol. 91, no. 21, pp. 9995-9999, 1994.

[125] K. I. Honma, S. Honma, and T. Hiroshige, "Critical role of food amount for prefeeding corticosterone peak in rats," The American Journal of Physiology, vol. 245, no. 3, pp. R339R344, 1983.

[126] A. Boulamery-Velly, N. Simon, J. Vidal, J. Mouchet, and B. Bruguerolle, "Effects of three-hour restricted food access during the light period on circadian rhythms of temperature, locomotor activity, and heart rate in rats," Chronobiology International, vol. 22, no. 3, pp. 489-498, 2005.

[127] R. Hara, K. Wan, H. Wakamatsu et al., "Restricted feeding entrains liver clock without participation of the suprachiasmatic nucleus," Genes to Cells, vol. 6, no. 3, pp. 269-278, 2001.

[128] J. Hirao, S. Arakawa, K. Watanabe, K. Ito, and T. Furukawa, "Effects of restricted feeding on daily fluctuations of hepatic functions including P450 monooxygenase activities in rats," Journal of Biological Chemistry, vol. 281, no. 6, pp. 31653171, 2006.

[129] R. E. Mistlberger, "Circadian food-anticipatory activity: formal models and physiological mechanisms," Neuroscience and Biobehavioral Reviews, vol. 18, no. 2, pp. 171-195, 1994.

[130] C. A. Comperatore and F. K. Stephan, "Entrainment of duodenal activity to periodic feeding," Journal of Biological Rhythms, vol. 2, no. 3, pp. 227-242, 1987.

[131] M. Saito, E. Murakami, and M. Suda, "Circadian rhythms in disaccharidases of rat small intestine and its relation to food intake," Biochimica et Biophysica Acta, vol. 421, no. 1, pp. 177-179, 1976. 
[132] K. Horikawa, Y. Minami, M. Iijima, M. Akiyama, and S. Shibata, "Rapid damping of food-entrained circadian rhythm of clock gene expression in clock-defective peripheral tissues under fasting conditions," Neuroscience, vol. 134, no. 1, pp. 335-343, 2005.

[133] K. Oishi, K. Miyazaki, and N. Ishida, "Functional CLOCK is not involved in the entrainment of peripheral clocks to the restricted feeding: entrainable expression of mPer 2 and BMAL1 mRNAs in the heart of Clock mutant mice on Jcl:ICR background," Biochemical and Biophysical Research Communications, vol. 298, no. 2, pp. 198-202, 2002.

[134] F. K. Stephan, J. M. Swann, and C. L. Sisk, "Anticipation of 24-hr feeding schedules in rats with lesions of the suprachiasmatic nucleus," Behavioral and Neural Biology, vol. 25, no. 3, pp. 346-363, 1979.

[135] F. Damiola, N. Le Minli, N. Preitner, B. Kornmann, F. Fleury-Olela, and U. Schibler, "Restricted feeding uncouples circadian oscillators in peripheral tissues from the central pacemaker in the suprachiasmatic nucleus," Genes and Development, vol. 14, no. 23, pp. 2950-2961, 2000.

[136] K. A. Stokkan, S. Yamazaki, H. Tei, Y. Sakaki, and M. Menaker, "Entrainment of the circadian clock in the liver by feeding," Science, vol. 291, no. 5503, pp. 490-493, 2001.

[137] J. D. Lin, C. Liu, and S. Li, "Integration of energy metabolism and the mammalian clock," Cell Cycle, vol. 7, no. 4, pp. 453457, 2008.

[138] H. Sherman, I. Frumin, R. Gutman et al., "Long-term restricted feeding alters circadian expression and reduces the level of inflammatory and disease markers," Journal of Cellular and Molecular Medicine, vol. 15, pp. 2745-2759, 2011.

[139] H. Sherman, Y. Genzer, R. Cohen, N. Chapnik, Z. Madar, and O. Froy, "Timed high-fat diet resets circadian metabolism and prevents obesity," FASEB Journal, vol. 26, pp. 3493-3502, 2012.

[140] J. J. Gooley, A. Schomer, and C. B. Saper, “The dorsomedial hypothalamic nucleus is critical for the expression of foodentrainable circadian rhythms," Nature Neuroscience, vol. 9, no. 3, pp. 398-407, 2006.

[141] G. J. Landry, M. M. Simon, I. C. Webb, and R. E. Mistlberger, "Persistence of a behavioral food-anticipatory circadian rhythm following dorsomedial hypothalamic ablation in rats," American Journal of Physiology, vol. 290, no. 6, pp. R1527-R1534, 2006.

[142] G. J. Landry, G. R. Yamakawa, I. C. Webb, R. J. Mear, and R. E. Mistlberger, "The dorsomedial hypothalamic nucleus is not necessary for the expression of circadian food-anticipatory activity in rats," Journal of Biological Rhythms, vol. 22, no. 6, pp. 467-478, 2007.

[143] M. Mieda, S. C. Williams, J. A. Richardson, K. Tanaka, and M. Yanagisawa, "The dorsomedial hypothalamic nucleus as a putative food-entrainable circadian pacemaker," Proceedings of the National Academy of Sciences of the United States of America, vol. 103, no. 32, pp. 12150-12155, 2006.

[144] A. J. Davidson, S. L. T. Cappendijk, and F. K. Stephan, "Feeding-entrained circadian rhythms are attenuated by lesions of the parabrachial region in rats," American Journal of Physiology, vol. 278, no. 5, pp. R1296-R1304, 2000.

[145] J. Mendoza, M. Angeles-Castellanos, and C. Escobar, "Differential role of the accumbens Shell and Core subterritories in food-entrained rhythms of rats," Behavioural Brain Research, vol. 158, no. 1, pp. 133-142, 2005.

[146] R. E. Mistlberger and D. G. Mumby, "The limbic system and food-anticipatory circadian rhythms in the rat: ablation and dopamine blocking studies," Behavioural Brain Research, vol. 47, no. 2, pp. 159-168, 1992.

[147] A. J. Davidson, "Search for the feeding-entrainable circadian oscillator: a complex proposition," American Journal of Physiology, vol. 290, no. 6, pp. R1524-R1526, 2006.

[148] R. E. Mistlberger and E. G. Marchant, "Enhanced foodanticipatory circadian rhythms in the genetically obese Zucker rat," Physiology and Behavior, vol. 66, no. 2, pp. 329335, 1999.

[149] S. Pitts, E. Perone, and R. Silver, "Food-entrained circadian rhythms are sustained in arrhythmic Clk/Clk mutant mice," American Journal of Physiology, vol. 285, no. 1, pp. R57-R67, 2003.

[150] J. S. Pendergast, W. Nakamura, R. C. Friday, F. Hatanaka, T. Takumi, and S. Yamazaki, "Robust food anticipatory activity in BMAL1-deficient mice," PLoS ONE, vol. 4, no. 3, Article ID e4860, 2009.

[151] K. F. Storch and C. J. Weitz, "Daily rhythms of foodanticipatory behavioral activity do not require the known circadian clock," Proceedings of the National Academy of Sciences of the United States of America, vol. 106, no. 16, pp. 6808-6813, 2009.

[152] C. A. Feillet, J. A. Ripperger, M. C. Magnone, A. Dulloo, U. Albrecht, and E. Challet, "Lack of food anticipation in Per2 mutant mice," Current Biology, vol. 16, no. 20, pp. 2016-2022, 2006.

[153] R. E. Mistlberger, "Circadian rhythms: perturbing a foodentrained clock," Current Biology, vol. 16, no. 22, pp. R968R969, 2006.

[154] E. J. Masoro, I. Shimokawa, Y. Higami, C. A. McMahan, and B. P. Yu, "Temporal pattern of food intake not a factor in the retardation of aging processes by dietary restriction," Journals of Gerontology A, vol. 50, no. 1, pp. B48-B53, 1995.

[155] J. Koubova and L. Guarente, "How does calorie restriction work?" Genes and Development, vol. 17, no. 3, pp. 313-321, 2003.

[156] E. J. Masoro, "Overview of caloric restriction and ageing," Mechanisms of Ageing and Development, vol. 126, no. 9, pp. 913-922, 2005.

[157] G. S. Roth, M. A. Lane, D. K. Ingram et al., "Biomarkers of caloric restriction may predict longevity in humans," Science, vol. 297, no. 5582, p. 811, 2002.

[158] G. S. Roth, J. A. Mattison, M. A. Ottinger, M. E. Chachich, M. A. Lane, and D. K. Ingram, "Aging in rhesus monkeys: relevance to human health interventions," Science, vol. 305, no. 5689, pp. 1423-1426, 2004.

[159] R. Weindruch and R. S. Sohal, "Caloric intake and aging," The New England Journal of Medicine, vol. 337, no. 14, pp. 986-994, 1997.

[160] E. Challet, I. Caldelas, C. Graff, and P. Pévet, "Synchronization of the molecular clockwork by light- and food-related cues in mammals," Biological Chemistry, vol. 384, no. 5, pp. 711-719, 2003.

[161] E. Challet, L. C. Solberg, and F. W. Turek, "Entrainment in calorie-restricted mice: conflicting zeitgebers and freerunning conditions," American Journal of Physiology, vol. 274, no. 6, pp. R1751-R1761, 1998.

[162] J. Mendoza, C. Graff, H. Dardente, P. Pevet, and E. Challet, "Feeding cues alter clock gene oscillations and photic responses in the suprachiasmatic nuclei of mice exposed to a light/dark cycle," Journal of Neuroscience, vol. 25, no. 6, pp. 1514-1522, 2005. 
[163] D. Resuehr and J. Olcese, "Caloric restriction and melatonin substitution: effects on murine circadian parameters," Brain Research, vol. 1048, no. 1-2, pp. 146-152, 2005.

[164] J. Mendoza, K. Drevet, P. Pévet, and E. Challet, "Daily meal timing is not necessary for resetting the main circadian clock by calorie restriction," Journal of Neuroendocrinology, vol. 20, no. 2, pp. 251-260, 2008.

[165] O. Froy, N. Chapnik, and R. Miskin, "Relationship between calorie restriction and the biological clock: lessons from longlived transgenic mice," Rejuvenation Research, vol. 11, no. 2, pp. 467-471, 2008.

[166] R. Michael Anson, Z. Guo, R. de Cabo et al., "Intermittent fasting dissociates beneficial effects of dietary restriction on glucose metabolism and neuronal resistance to injury from calorie intake," Proceedings of the National Academy of Sciences of the United States of America, vol. 100, no. 10, pp. 6216-6220, 2003.

[167] O. Descamps, J. Riondel, V. Ducros, and A. M. Roussel, "Mitochondrial production of reactive oxygen species and incidence of age-associated lymphoma in OF1 mice: effect of alternate-day fasting," Mechanisms of Ageing and Development, vol. 126, no. 11, pp. 1185-1191, 2005.

[168] C. L. Goodrick, D. K. Ingram, M. A. Reynolds, J. R. Freeman, and N. Cider, "Effects of intermittent feeding upon weight and lifespan in inbred mice: interaction of genotype and age," Mechanisms of Ageing and Development, vol. 55, no. 1, pp. 6987, 1990.

[169] I. Ahmet, R. Wan, M. P. Mattson, E. G. Lakatta, and M. Talan, "Cardioprotection by intermittent fasting in rats," Circulation, vol. 112, no. 20, pp. 3115-3121, 2005.

[170] A. Contestabile, E. Ciani, and A. Contestabile, "Dietary restriction differentially protects from neurodegeneration in animal models of excitotoxicity," Brain Research, vol. 1002, no. 1-2, pp. 162-166, 2004.

[171] D. E. Mager, R. Wan, M. Brown et al., "Caloric restriction and intermittent fasting alter spectral measures of heart rate and blood pressure variability in rats," FASEB Journal, vol. 20, no. 6, pp. 631-637, 2006.

[172] M. P. Mattson, "Energy intake, meal frequency, and health: a neurobiological perspective," Annual Review of Nutrition, vol. 25, pp. 237-260, 2005.

[173] S. Sharma and G. Kaur, "Neuroprotective potential of dietary restriction against kainate-induced excitotoxicity in adult male Wistar rats," Brain Research Bulletin, vol. 67, no. 6, pp. 482-491, 2005.

[174] M. P. Mattson, "Dietary factors, hormesis and health," Ageing Research Reviews, vol. 7, no. 1, pp. 43-48, 2008.

[175] M. P. Mattson, W. Duan, R. Wan, and Z. Guo, "Prophylactic activation of neuroprotective stress response pathways by dietary and behavioral manipulations," NeuroRx, vol. 1, no. 1, pp. 111-116, 2004.

[176] O. Froy, N. Chapnik, and R. Miskin, "Effect of intermittent fasting on circadian rhythms in mice depends on feeding time," Mechanisms of Ageing and Development, vol. 130, no. 3, pp. 154-160, 2009.

[177] H. Yanagihara, H. Ando, Y. Hayashi, Y. Obi, and A. Fujimura, "High-fat feeding exerts minimal effects on rhythmic mRNA expression of clock genes in mouse peripheral tissues," Chronobiology International, vol. 23, no. 5, pp. 905-914, 2006.

[178] A. Kohsaka, A. D. Laposky, K. M. Ramsey et al., "High-fat diet disrupts behavioral and molecular circadian rhythms in mice," Cell Metabolism, vol. 6, no. 5, pp. 414-421, 2007.
[179] M. Barnea, Z. Madar, and O. Froy, "High-fat diet delays and fasting advances the circadian expression of adiponectin signaling components in mouse liver," Endocrinology, vol. 150, no. 1, pp. 161-168, 2009.

[180] M. Barnea, Z. Madar, and O. Froy, "High-fat diet followed by fasting disrupts circadian expression of adiponectin signaling pathway in muscle and adipose tissue," Obesity, vol. 18, no. 2, pp. 230-238, 2010.

[181] P. Cano, V. Jimenez-Ortega, A. Larrad, C. F. R. Toso, D. P. Cardinali, and A. I. Esquifino, "Effect of a high-fat diet on 24-h pattern of circulating levels of prolactin, luteinizing hormone, testosterone, corticosterone, thyroid-stimulating hormone and glucose, and pineal melatonin content, in rats," Endocrine, vol. 33, no. 2, pp. 118-125, 2008.

[182] M. C. Cha, C. J. Chou, and C. N. Boozer, "High-fat diet feeding reduces the diurnal variation of plasma leptin concentration in rats," Metabolism: Clinical and Experimental, vol. 49, no. 4, pp. 503-507, 2000.

[183] P. J. Havel, R. Townsend, L. Chaump, and K. Teff, "Highfat meals reduce 24 -h circulating leptin concentrations in women," Diabetes, vol. 48, no. 2, pp. 334-341, 1999.

[184] J. Mendoza, P. Pévet, and E. Challet, "High-fat feeding alters the clock synchronization to light," Journal of Physiology, vol. 586, no. 24, pp. 5901-5910, 2008.

[185] M. Hatori, C. Vollmers, A. Zarrinpar et al., "Time-restricted feeding without reducing caloric intake prevents metabolic diseases in mice fed a high-fat diet," Cell Metabolism, vol. 15, pp. 848-860, 2012. 


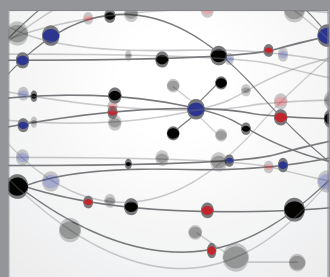

The Scientific World Journal
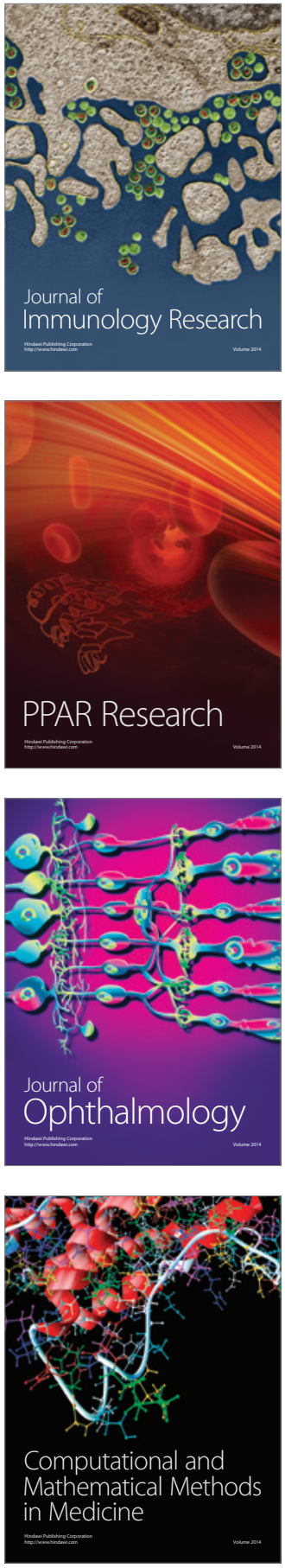

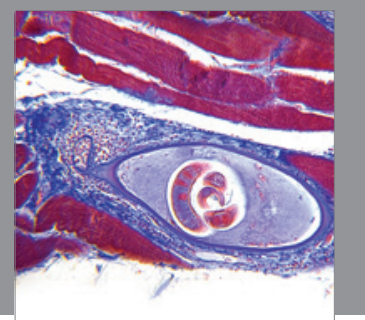

Gastroenterology

Research and Practice
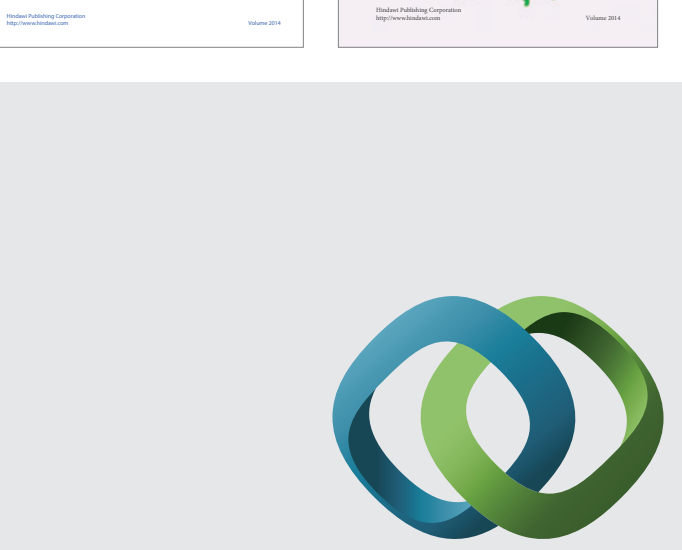

\section{Hindawi}

Submit your manuscripts at

http://www.hindawi.com
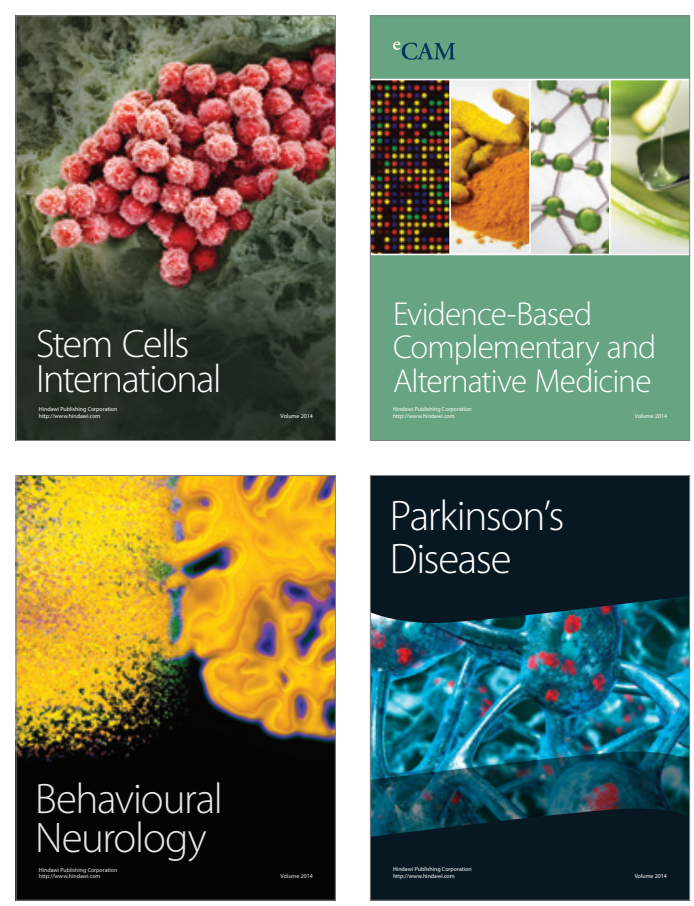

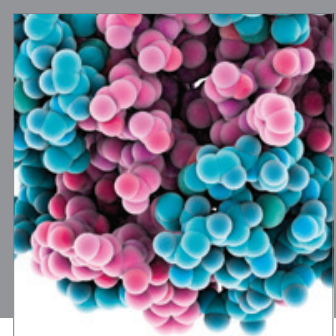

Journal of
Diabetes Research

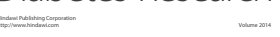

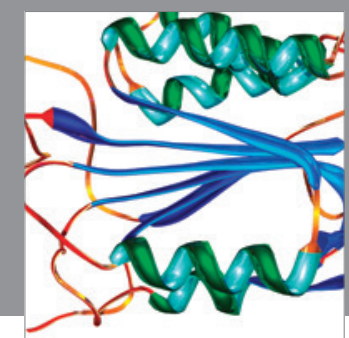

Disease Markers
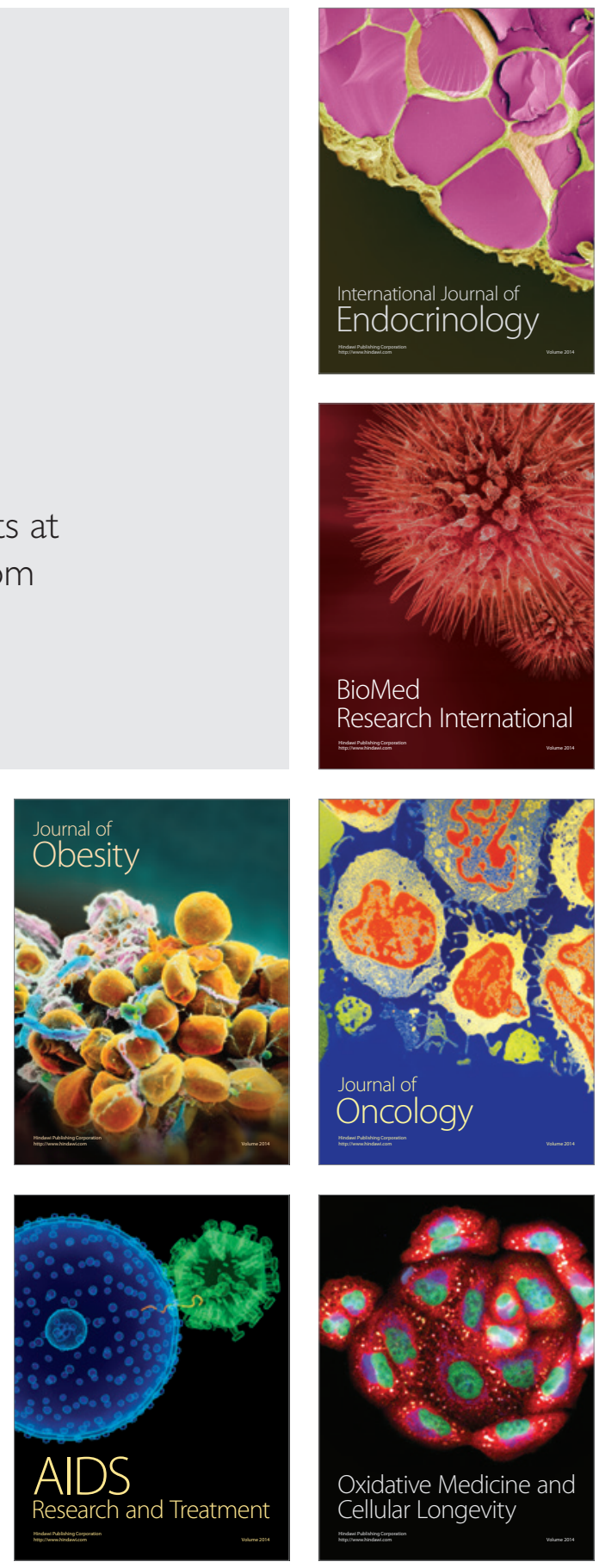